\title{
Téoros
}

Revue de recherche en tourisme

\section{La formation en tourisme}

\section{Sylvie Gagnon}

Volume 11, numéro 1, mars 1992

La formation en tourisme : à la croisée des chemins

URI : https://id.erudit.org/iderudit/1078939ar

DOI : https://doi.org/10.7202/1078939ar

Aller au sommaire du numéro

Éditeur(s)

Université du Québec à Montréal

ISSN

0712-8657 (imprimé)

1923-2705 (numérique)

Découvrir la revue

Citer ce document

Gagnon, S. (1992). La formation en tourisme. Téoros, 11(1), 2-2.

https://doi.org/10.7202/1078939ar

Ce document est protégé par la loi sur le droit d'auteur. L'utilisation des services d'Érudit (y compris la reproduction) est assujettie à sa politique d'utilisation que vous pouvez consulter en ligne.

https://apropos.erudit.org/fr/usagers/politique-dutilisation/
Cet article est diffusé et préservé par Érudit.

Érudit est un consortium interuniversitaire sans but lucratif composé de l’Université de Montréal, l'Université Laval et l'Université du Québec à Montréal. Il a pour mission la promotion et la valorisation de la recherche. https://www.erudit.org/fr/ 


\section{Présentation}

Sylvie Gagnon

\section{La formation en tourisme}

En 1975, quandj'étais étudiante en Techniques de tourisme au CEGEP de Granby, mes professeurs me disaient quele tourisme était l'industrie de l'avenir. Même discours quelques années plus tard au moment de mes études à I'UOAM en Gestion et intervention touristiques. En 1986, après un an passé au Centre des hautes études touristiques à Aix-en-Provence (France), je ramenais le même écho dans mes bagages mais renforcit par une vision plus internationale de cette industrie. Aujourd'hui que je suis professeur, quand mes étudiants m'interrogent sur les perspectives d'emplois dans le domaine et me rapportent les paroles d'un politicien, d'un conférencier ou même d'un de mes confrères de I'UQAM à l'effet que le tourisme sera l'industrie de l'an 2000, j'ai peineà retenir un petit sourire. Ca fait dix-sept ans que j'entends dire que c'est pour demain..

Dix sept années pendant lesquelles ce sont multipliés les programmes de formation, les écoles, et les cours de toute nature (temps plein, temps partiel, formation continue, formation sur mesure, formation en entreprise...) touchant directement ou indirectement le phénomène touristique. En 1983, Téoros dans un numéro sur la "Formation et les conditions de travailen tourisme" tentait un premier constat: la nécessité d'une formation multidisciplinaire auxniveaux collégial et universitaire maisla plus oumoins grande reconnaissance de cette formation dans lindustrie; la place essentielle que devrait occuper le capital humain dans les entreprises touristiques (davantage que dansn'importe quelautre secteur industriell); des conditions de travail peu envieuses dans une industrie non intégrée, sousdéveloppée et non-spécialisée: bas salaires, longues heures de travail, modes rudimentaires de sélection et de promotion des employés, etc.

Après presque dix ans - et quelques milliers de diplômés de plus sur le marché - oủ en sommes-nous ( $C$. Bélanger)? Au moment oú le monde de l'éducation lautant du coté de la formation professionnelle que de la formation généralel est accusé de tous les maux, où le gouvernement procède à des réformes majeures (S. Gagnon et $R$. Prévost) tout en injectant de plus en plus d'argent dans la formation sur mesure (M.A. Délisle, J.C. Rayon et B. Morneau), il importe de refaire à nouveau le bilan mais cette fois-cien regard des nouveaux défis que doit relever l'industrie touristique en cette décennie de fin de siècle. Défis quidejà interpellentles milieux de formationen terme de contenu (L.Jolin), d"outils pédagogiques (J.M. Descôteaux et M.Archambault) et d"une meilleure adéquation industrie/ecole (D. Sirois et A.Muller-Hehn).

Ceprésent numéro de Téoros sur la formation, ne serait-ce que par la diversité et la quantité de contribution qu'il a suscitées, dénote déjà une nette volonté dans le milieu de la formation d'améliorer la qualité de l'enseignement et de l'ajuster aux besoins du marché du travail. Par contre, après plus de 20 ans de formation en tourisme au Québec, le "savoir touristique" et ses diplömés (J. Stafford et R. Nadeau) n'ont peut être pas encore toute la place qu'il faudrait leur donner aujourd'hui dans cette industrie pour qu'elle devienne (enfin!) celle de demain...

Ce numéro se veut donc une contribution à l"effort collectif de réflexion et de questionnement que nous devons tous faire ensemble pour le mieux être de notre industrie présente... et future.

Bonne lecture! $f$ 